\title{
Como fazer uma correta prescrição medicamentosa e quais os importantes cuidados?
}

\author{
How to make a correct prescription of medicines \\ and what are the important precautions?
}

\section{Karoline Ferreira Farias Catarino}

Aluna da Faculdade de Odontologia da Universidade Federal Fluminense - UFF, Niterói/RJ.

\section{Suelen Cristina Sartoretto Lorenzzi}

Pós - doutora em Odontologia da Universidade Federal Fluminense - UFF, Niterói/ RJ.

\section{Marcelo José Pinheiro Guedes de Uzeda}

Professor de Cirurgia Oral Menor e Anestesiologia da Faculdade de Odontologia da Universidade Federal Fluminense - UFF, Niterói/RJ.

\section{Rafael Seabra Louro}

Professor de Cirurgia Oral Menor e Anestesiologia da Faculdade de Odontologia da Universidade Federal Fluminense - UFF, Niterói/RJ.

\section{Mônica Diuana Calasans Maia}

Professora de Cirurgia Oral Menor e Anestesiologia da Faculdade de Odontologia da Universidade Federal Fluminense - UFF, Niterói/RJ.

\section{Josiane Costa Rodrigues de Sá}

Professora de Clínica Diagnóstica da Faculdade de Odontologia da Universidade Federal Fluminense - UFF, Niterói/RJ.

\section{Adriana Terezinha Neves Novellino Alves}

Professora de Clínica Diagnóstica da Faculdade de Odontologia da Universidade Federal Fluminense - UFF, Niterói/RJ.

\section{Simone Saldanha Ignácio de Oliveira}

Professora de Oclusão e Clínica de DTM da Faculdade de Odontologia da Universidade Federal Fluminense - UFF, Niterói/RJ.

\section{Rodrigo Figueiredo de Brito Resende}

Professor de Cirurgia Oral Menor e Anestesiologia da Faculdade de Odontologia da Universidade Federal Fluminense - UFF, Niterói/RJ.

Instituição na qual o trabalho foi realizado: Faculdade de Odontologia da Universidade Federal Fluminense Niterói/RJ.

Categoria: Revisão de literatura

\section{Informações do autor principal:}

Nome: Rodrigo Figueiredo de Brito Resende

Endereço: Rua Mário Santos Braga, 28, Faculdade de Odontologia.

E-mail: resende.r@hotmail.com

Telefone: (21) 997399282 


\title{
RESUMO
}

A inadequada prescrição de medicamentos na clínica odontológica deve-se, principalmente, ao escasso conhecimento dos acadêmicos de odontologia a respeito da farmacologia e da terapêutica. A falta de informação adequada aos estudantes acerca da indicação, da forma de administração, da posologia e dos efeitos adversos resultam em insegurança no momento de prescrever uma correta receita. É necessário que o medicamento seja prescrito adequadamente bem como ressalte a forma farmacêutica, a dose e o período de duração do tratamento. Nesse contexto, baseado nos principais livros de farmacologia da odontologia, foi criado uma tabela com os medicamentos indispensáveis na clínica odontológica associado com o correspondente nome de princípio ativo, o nome fantasia, a apresentação, a posologia, a via de administração e as possíveis observações acerca do fármaco. Além da descrição de uma receita com as principais normas, configurando-se como um manual de prescrição medicamentosa de fácil acesso para que os estudantes esclareçam suas possíveis dúvidas. Assim sendo, o objetivo deste trabalho é facilitar o entendimento dos alunos quanto a forma de prescrever medicamentos a fim de evitar incoerências e possíveis erros de prescrição advindas de alunos. Dessa forma, uma prescrição clara e objetiva tem como resultado a minimização de possíveis erros e, consequentemente, oferece maior segurança terapêutica e maior eficácia ao tratamento.

Palavras - Chave: Prescrição; Farmacologia; Odontologia.

\begin{abstract}
An inadequate prescription of medicines in the dental clinic must be, mainly, due to the little knowledge of dentistry students and respect to pharmacology and therapeutics. The lack of adequate information for students about indication, form of administration, dosage and adverse effects results in insecurity when prescribing a correct prescription. It is necessary that the drug is prescribed, as well as the pharmaceutical form, the dose and the duration of the treatment. In this context, based on the main pharmacology of dentistry books, a table was created with the essential medicines in the dental clinic associated with the name of active active ingredient, the active fancy name, the fancy name, a presentation, a dosage, route of administration and the following uses for making a drug. In addition to the description of a recipe with the main rules, configure it as a prescription drug manual easily accessible to students who clarify their possible doubts. Therefore, the objective of this work is to facilitate students' understanding of how to prescribe medications to avoid inconsistencies and possible errors of advanced prescription by students. Thus, a clear and objective prescription results in the minimization of possible errors and, consequently, offers greater therapeutic safety and greater efficacy to treatment.
\end{abstract}

Key words: Prescription; Pharmacology; Dentistry. 


\section{INTRODUÇÃO}

De acordo com a Lei $\mathrm{n}^{\circ} 5.081 / 66$, que regulamenta o exercício da Odontologia no Brasil, o cirurgião - dentista é apto para prescrever medicamentos. No entanto, na prática clínica acadêmica, é possível observar o sentimento de insegurança em relação à prescrição medicamentosa por parte dos estudantes de odontologia. Esse quadro tornase preocupante visto que o graduando de hoje é o profissional de amanhã.

Nesse sentido, PEPE E CASTRO (2000) relatam que a prática clínica no consultório odontológico se depara muitas vezes com dúvidas e inseguranças, principalmente com relação às consequências das tomadas de decisões decorrentes de seus riscos e benefícios. Isso se configura como um reflexo da fragmentação do ensino em farmacologia e distanciamento com a terapêutica medicamentosa durante a graduação de odontologia.

Em decorrência dessa fragilidade, desde a escolha do medicamento apropriado à elaboração da receita, é notório o impasse do aluno em redigir um receituário apropriado nas clínicas universitárias. É necessário ressaltar que a maioria dos erros de medicação ocorre no estágio de prescrição, o que pode comprometer a compreensão, qualidade e efetividade do tratamento farmacológico, bem como predispor ao aparecimento de eventos adversos. Ademais, a prescrição de medicamento busca garantir ao paciente os benefícios de sua administração e limitar a automedicação, devendo sua confecção se basear nas normas relativas aos medicamentos vigentes do País. (SOUZA ET AL, 2011)

Diante disso, é importante que o cirurgião-dentista compreenda e saiba aplicar devidamente a terapia medicamentosa durante o cuidado e manejo de seus pacientes bem como, orientá-los através de uma prescrição correta, atentando-se a essencialmente aos medicamentos mais comumente usados em odontologia como os analgésicos, antibióticos, ansiolíticos, anti-inflamatórios esteroidais e não esteroidais e até mesmo os anestésicos locais.. Dessa forma, o conhecimento acerca da farmacologia associado a prescrição e suas normas de elaboração são indispensáveis para o sucesso clínico, o que contribui para o uso racional dos medicamentos com maior segurança terapêutica, maior eficácia dos tratamentos e redução de erros de medicação.

Baseado nesse contexto, foi confeccionada uma tabela com os principais medicamentos utilizados na clínica odontológica associado com o correspondente nome de princípio ativo, os nomes de fantasia mais conhecidos, a apresentação, a posologia, a via de administração e as possíveis observações acerca do fármaco. Além da descrição de 
uma receita com as principais normas, configurando-se como um manual de prescrição medicamentosa de fácil acesso para que os estudantes esclareçam suas possíveis dúvidas. À vista disso, o objetivo deste trabalho é facilitar o entendimento dos alunos quanto a forma de prescrever medicamentos e evitar incoerências e possíveis erros de prescrição.

\section{REVISÃO DE LITERATURA}

\section{II.1 Tabela de medicamentos}

\begin{tabular}{|c|c|c|c|c|}
\hline \multicolumn{4}{|c|}{ LEGENDA } \\
\hline ANTIBIÓTICO & CORTICOIDE & AINES & ANALGÉSICO & OPIOIDE \\
\hline ANTIFUNGICO & BENZODIAZEPÍNICOS & RELAXANTE MUSCULAR & $\begin{array}{c}\text { INDICADO NA } \\
\text { ESTOMATOLOGIA }\end{array}$ \\
\hline
\end{tabular}

\begin{tabular}{|c|c|c|c|}
\hline $\begin{array}{l}\text { Nome do princípio ativo } \\
\text { (Nome fantasia) } \\
\text { (Apresentação) }\end{array}$ & Posologia & $\begin{array}{c}\text { Via de } \\
\text { administração }\end{array}$ & Observações clínicas \\
\hline $\begin{array}{c}\text { Amoxicilina } \\
\left(\text { Amox }^{\circledR} ; \text { Amiclavin }^{\circledR} ; \text { Amoximed }^{\circledR}\right) \\
(\text { Comprimido })\end{array}$ & $\begin{array}{c}\text { Terapêutico: } 500 \mathrm{mg} \text { de } 08 \text { em } 08 \\
\text { horas } \\
\begin{array}{c}\text { Profilático: } 2 \mathrm{~g} 01 \text { hora antes do } \\
\text { procedimento }\end{array}\end{array}$ & Uso interno/Via Oral & $\begin{array}{l}\text { - A amoxicilina pode afetar a flora } \\
\text { intestinal levando à uma menor } \\
\text { absorção de estrógenos, reduzindo } \\
\text { assim a efetividade dos } \\
\text { contraceptivos orais; } \\
\text { - A administração concomitante de } \\
\text { alopurinol durante o tratamento com } \\
\text { amoxicilina pode aumentar a } \\
\text { probabilidade de reação alérgica; } \\
\text { - } 1^{\circ} \text { opção do protocolo para } \\
\text { endocardite bacteriana segundo } \\
\text { AHA,2017; } \\
\text { - Bactericida; } \\
\text { - Espectro limitado; } \\
\text { - < toxidade; } \\
\text { - Poucos efeitos colaterais; } \\
\text { - Quando prescrito a receita (tipo } \\
\text { C), tem validade de } 10 \text { dias (RDC } \\
\text { no 20/2011). }\end{array}$ \\
\hline $\begin{array}{c}\text { Clindamicina } \\
\left(\text { Clindarix }^{\circledR} ; \text { Clindacin }^{\circledR} ; \text { Zindaclin }^{\circledR}\right) \\
(\text { Comprimido })\end{array}$ & $\begin{array}{l}\text { Terapêutico: } 300 \text { mg ou } 600 \text { mg de } \\
06 \text { em } 06 \text { horas ou de } 08 \text { em } 08 \text { horas } \\
\text { Profilático: } 600 \text { mg } 01 \text { hora antes do } \\
\text { procedimento }\end{array}$ & Uso interno/Via Oral & $\begin{array}{l}\text { - } 1^{\circ} \text { opção para pacientes alérgicos } \\
\text { a amoxicilina. } \\
\text { - } 1^{\circ} \text { opção para pacientes alérgicos } \\
\text { a amoxicilina no protocolo para } \\
\text { endocardite bacteriana, segundo } \\
\text { AHA,2017. } \\
\text { - Efeito adverso: colite } \\
\text { pseudomembranosa (quando dose } \\
\text { diária menor que } 1200 \text { mg). } \\
\text { - Efetiva contra cocos aeróbios } \\
\text { Gram + e Anaeróbios bucais; } \\
\text { - Atinge altos níveis ósseos; } \\
\text { - Bacteriostático (Doses normais) e } \\
\text { Bactericida (Altas doses); } \\
\text { - Indicado para os casos de } \\
\text { osteomielite; } \\
\text { - Quando prescrito a receita (tipo } \\
\text { C), tem validade de } 10 \text { dias (RDC } \\
\text { no 20/2011). }\end{array}$ \\
\hline
\end{tabular}




\begin{tabular}{|c|c|c|c|}
\hline $\begin{array}{c}\text { Azitromicina } \\
\left(\text { Azimix }^{\circledast} ; \text { Azalide }^{\circledR} ; \text { Ems-Max }{ }^{\circledR}\right) \\
\text { (Comprimido) }\end{array}$ & $\begin{array}{l}\text { Terapêutico: } 500 \mathrm{mg} \text { de } 24 \mathrm{em} 24 \text { horas } \\
\text { Profilático: } 500 \mathrm{mg} 01 \text { hora antes do } \\
\text { procedimento }\end{array}$ & Uso interno/Via Oral & $\begin{array}{l}\text { - Contraindicado em indivíduos com } \\
\text { hipersensibilidade a qualquer } \\
\text { antibiótico macrolídeo; } \\
\text { - Apresenta concentração elevada } \\
\text { no interior dos neutrófilos, } \\
\text { resultando em concentrações } \\
\text { elevadas nos tecidos infectados; } \\
\text { - 20 opção para pacientes alérgicos } \\
\text { a amoxicilina segundo AHA,2017; } \\
\text { - Quando prescrito a receita (tipo C), } \\
\text { tem validade de } 10 \text { dias (RDC noo } \\
\text { 20/2011). }\end{array}$ \\
\hline $\begin{array}{l}\text { Metronidazol } \\
\text { (Nidazofarma }^{\circledR} ; \text { Metronack }^{\circledR} ; \\
\text { Metronidazol Benz }^{\circledR} \text { ) } \\
\text { (Comprimido) }\end{array}$ & $\begin{array}{l}\text { Terapêutico: } 250 \mathrm{mg} \text { de } 08 \mathrm{em} 08 \text { horas } \\
\text { ou } 400 \mathrm{mg} \text { de } 12 \mathrm{em} 12 \text { horas }\end{array}$ & Uso interno/Via Oral & $\begin{array}{l}\text { - Efeito dissulfiram (ou antabuse }{ }^{\circledR} \text { ), } \\
\text { quando administrado juntamente } \\
\text { com álcool; } \\
\text { - Bactericida; } \\
\text { - Pode potencializar o efeito dos } \\
\text { anticoagulantes; } \\
\text { - Quando prescrito a receita (tipo C), } \\
\text { tem validade de } 10 \text { dias (RDC no } \\
\text { 20/2011). }\end{array}$ \\
\hline $\begin{array}{c}\text { Amoxicilina + Clavulanato de } \\
\text { potássio } \\
\text { (Novamox }^{\circledR} ; \text { Amplamox } A c^{\circledast} ; \\
\left.\text { Clavulin }{ }^{\circledast}\right) \\
\text { (Comprimido) }\end{array}$ & $\begin{array}{l}\text { Terapêutico: } 500 \mathrm{mg}+125 \mathrm{mg} \text { de } 08 \\
\text { em } 08 \text { horas }\end{array}$ & Uso interno/Via Oral & $\begin{array}{l}\text { - Medicamento contém fenilalanina; } \\
\text { - Contraindicada para pacientes } \\
\text { com histórico prévio de } \\
\text { icterícia/disfunção hepática } \\
\text { associada ao seu uso ou ao uso da } \\
\text { penicilina; } \\
\text { - Evitar o uso concomitante com } \\
\text { Nimesulida, Paracetamol e àlcool, } \\
\text { em virtude de maior chance de lesão } \\
\text { hepática; } \\
\text { - Quando prescrito a receita (tipo C), } \\
\text { tem validade de } 10 \text { dias (RDC no } \\
20 / 2011 \text { ). }\end{array}$ \\
\hline $\begin{array}{c}\text { Clorexidina } \\
\left.\text { (Noplak }^{\circledR} ; \text { Periogard }{ }^{\circledR} ; \text { Peroxidin }^{\circledR}\right) \\
\text { (Solução e gel) }\end{array}$ & $\begin{array}{l}\text { 0,12\%: } 5 \mathrm{ml} \text { do enxaguatório, bochechar } \\
\text { por } 1 \text { minuto previamente aos } \\
\text { procedimentos clínicos/cirúrgicos em } \\
\text { Odontologia. } \\
\text { Quando prescrito para uso domiciliar, } \\
\text { bochechar } 2 \text { ou } 3 \text { vezes ao dia por } 01 \\
\text { minuto. No caso de procedimentos } \\
\text { cirúrgicos, não realizar bochechos, } \\
\text { apenas banhar a região nas primeiras } 48 \\
\text { horas. } \\
0.2 \% \text { Gel: aplicar na ferida cirúrgica } 2 \text { ou } \\
3 \text { vezes. }\end{array}$ & $\begin{array}{l}\text { Uso interno/Via } \\
\text { Bucal }\end{array}$ & $\begin{array}{l}\text { - Aguardando de } 30 \text { minutos a } 2 \\
\text { horas após a escovação para poder } \\
\text { realizar os bochechos, que devem } \\
\text { durar aproximadamente } 1 \text { minuto. } \\
\text { - Não se deve enxaguar a boca } \\
\text { após o bochecho; } \\
\text { - Não prolongar seu uso por mais de } \\
14 \text { dias. }\end{array}$ \\
\hline 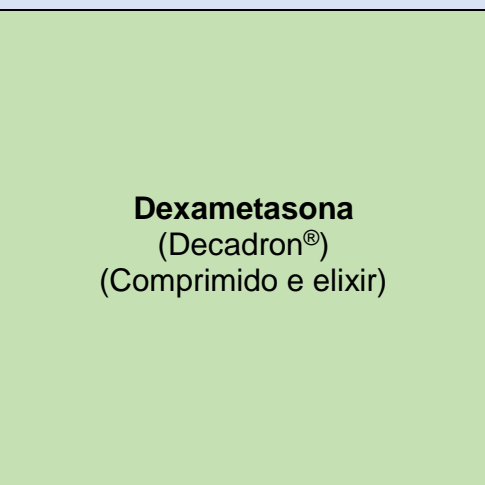 & $\begin{array}{l}\text { Profilático: } 4 \mathrm{mg}, 2 \text { comprimidos } 01 \\
\text { hora antes do procedimento. } \\
\text { Terapêutico: Tomar } 01 \text { comprimido de } \\
08 \text { em } 08 \text { ou de } 12 \text { em } 12 \text { horas } \\
\text { (dependendo da indicação do } \\
\text { tratamento). } \\
\text { Elixir: Espalhar pela boca a medida de } \\
01 \text { colher de sopa ( } 10 \mathrm{~mL} \text { ), por } 01 \text { a } 03 \\
\text { minutos. } 03 \text { vezes ao dia. Durante } 15 \\
\text { dias. }\end{array}$ & $\begin{array}{l}\text { Uso interno/Via Oral } \\
\text { Uso interno/Via } \\
\text { Bucal }\end{array}$ & $\begin{array}{l}\text { - Contraindicado para infecções } \\
\text { fúngicas sistêmicas, } \\
\text { hipersensibilidade a sulfitos ou a } \\
\text { qualquer outro componente do } \\
\text { medicamento e administração de } \\
\text { vacinas de vírus vivo, glaucoma } \\
\text { primário, herpes simples ocular, } \\
\text { tuberculose e psicose aguda. }\end{array}$ \\
\hline
\end{tabular}




\begin{tabular}{|c|c|c|c|}
\hline $\begin{array}{c}\text { Triancinolona acetonida } \\
\left(\text { Omcilon A Orobase }{ }^{\circledR} ; \text { Mud Oral }{ }^{\circledR}\right) \\
\text { (Pasta) }\end{array}$ & $\begin{array}{l}\text { Pasta (Bisnaga): Aplicar sem esfregar } \\
\text { na lesão previamente seca até se } \\
\text { desenvolver uma película fina, } 3 \text { vezes } \\
\text { ao dia. }\end{array}$ & $\begin{array}{c}\text { Uso interno/Via } \\
\text { Bucal }\end{array}$ & $\begin{array}{l}\text { - Contraindicado em pacientes com } \\
\text { tuberculose, úlcera péptica ou } \\
\text { diabetes mellitus, glaucoma } \\
\text { primário, herpes simples ocular e } \\
\text { psicose aguda. }\end{array}$ \\
\hline $\begin{array}{c}\text { Acetonindo de Triancinolona + } \\
\text { Sulfato de neomicina + } \\
\text { Gramicidina + Nistatina } \\
\left.\text { (Omcilon A “M" }{ }^{\circledR}\right) \\
\text { (Pomada) }\end{array}$ & 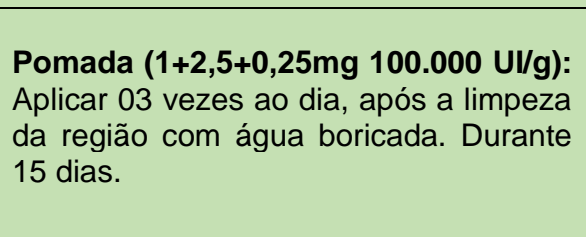 & $\begin{array}{l}\text { Uso interno/Via } \\
\text { Bucal }\end{array}$ & $\begin{array}{l}\text { - Indicação: Queilite angular, } \\
\text { Queilite actínica e Candidíase } \\
\text { hiperplásica em lábio. } \\
\text { - Contraindicado em glaucoma } \\
\text { primário, herpes simples ocular, } \\
\text { tuberculose e psicose aguda. }\end{array}$ \\
\hline $\begin{array}{c}\text { Betametasona } \\
\left(\text { Celestone }{ }^{\circledR}\right) \\
\text { (Comprimido e elixir) }\end{array}$ & $\begin{array}{l}\text { Elixir: Espalhar pela boca a medida de } \\
01 \text { colher de sopa }(10 \mathrm{~mL}) \text {, por } 01 \text { a } 03 \\
\text { minutos. } 03 \text { vezes ao dia. Durante } 15 \\
\text { dias. }\end{array}$ & $\begin{array}{l}\text { Uso interno/Via } \\
\text { Bucal }\end{array}$ & $\begin{array}{l}\text { - Contraindicado em pacientes com } \\
\text { doença fúngica sistêmica, primário, } \\
\text { herpes simples ocular, tuberculose e } \\
\text { psicose aguda. }\end{array}$ \\
\hline $\begin{array}{l}\text { Propionato de clobetasol } \\
\text { (Psorex }{ }^{\circledR} ; \text { Farmácia de } \\
\text { manipulação) } \\
\text { (Creme) }\end{array}$ & $\begin{array}{l}\text { Creme } \mathbf{0 , 5} \mathbf{~ m g / g : ~ A p l i c a r ~ n a ~ l e s a ̃ o ~} 3 \\
\text { vezes ao dia. Por no máximo } 15 \text { dias. }\end{array}$ & $\begin{array}{l}\text { Uso interno/Via } \\
\text { Bucal }\end{array}$ & $\begin{array}{l}\text { - Indicação: psoríase, líquen plano, } \\
\text { lúpus eritematoso, eczema } \\
\text { recalcitrantes, pênfigo, penfigóide } \\
\text { das membranas mucosas. } \\
\text { - Contraindicado em glaucoma } \\
\text { primário, herpes simples ocular, } \\
\text { tuberculose e psicose aguda. }\end{array}$ \\
\hline $\begin{array}{c}\text { Prednisona } \\
\left.\text { (Predcort }^{\circledR} ; \text { Prednis }^{\circledR} ; \text { Corticorten }{ }^{\circledR}\right) \\
(\text { Comprimido })\end{array}$ & $\begin{array}{l}\text { Terapêutico: } 5 \text { ou } 20 \mathrm{mg} \text { - Dose inicial } \\
\text { de } 40 \text { a } 60 \mathrm{mg} \text {, com desmame } \\
\text { progressivo até a dose final de } 5 \mathrm{mg} \text {. } \\
\text { Máximo de } 15 \text { dias. }\end{array}$ & Uso interno/Via Oral & $\begin{array}{l}\text { - Indicação: Pênfigo, dermatite } \\
\text { bolhosa herpetiforme, eritema } \\
\text { multiforme grave (síndrome de } \\
\text { Stevens-Johnson), desordens } \\
\text { mediadas imunologicamente, } \\
\text { penfigóide das membranas } \\
\text { mucosas, líquen plano. } \\
\text { - Contraindicado em glaucoma } \\
\text { primário, herpes simples ocular, } \\
\text { tuberculose psicose aguda. }\end{array}$ \\
\hline $\begin{array}{c}\text { Nimesulida } \\
\left.\text { (Scaflam }^{\circledR} ; \text { Cimelide }^{\circledR} ; \text { Arflex }^{\circledR}\right) \\
(\text { Comprimido })\end{array}$ & $\begin{array}{l}\text { Terapêutico: } 100 \text { mg de } 12 \text { em } 12 \text { horas } \\
\text { Terapêutico: } 200 \text { mg de } 24 \text { em } 24 \text { horas }\end{array}$ & Uso interno/Via Oral & $\begin{array}{l}\text { - Não usar em pacientes com } \\
\text { histórico de alergia a aspirina; } \\
\text { - Máximo de dias para a duração do } \\
\text { tratamento: } 2 \text { à 3; } \\
\text { - Não usar com álcool, paracetamol } \\
\text { e clavulanato de potássio } \\
\text { associados (Devido à } \\
\text { hepatotoxicidade); } \\
\text { - Contraindicado para pacientes } \\
\text { asmáticos; } \\
\text { - Inibidor seletivo para COX-2. }\end{array}$ \\
\hline $\begin{array}{c}\text { lbuprofeno } \\
\left.{\text { (Advi }{ }^{\circledR} ; \text { Alivium }^{\circledR} ; \text { Buscofem }}^{\circledR}\right) \\
(\text { Comprimido revestido })\end{array}$ & $\begin{array}{l}\text { Terapêutico: } 400 \mathrm{mg} \text { de } 06 \text { em } 06 \text { horas } \\
\text { Terapêutico: } 600 \mathrm{mg} \text { de } 08 \text { em } 08 \text { horas } \\
\text { Terapêutico: } 200 \mathrm{mg} / \mathrm{mL} \text {. Pacientes } \\
\text { pediátricos com mais de } 30 \mathrm{~kg} \text { não } \\
\text { devem exceder a dose máxima de } 20 \\
\text { gotas. Para adultos, } 20 \text { a } 80 \text { gotas, não } \\
\text { excedendo a dose máxima de } 3.200 \\
\text { mg/dia. } \\
\text { Terapêutico: Dose pediátrica: } 50 \\
\text { mg/ml de } 06 \text { em } 06 \text { horas }\end{array}$ & Uso interno/Via Oral & $\begin{array}{l}\text { - Não usar com inibidores da } \\
\text { Enzima Conversora da } \\
\text { Angiotensina; } \\
\text { - Máximo de dias para a duração do } \\
\text { tratamento: } 2 \text { à } 3 \text {; } \\
\text { - AINES indicado para pacientes } \\
\text { pediátricos } 200 \mathrm{mg} / \mathrm{mL} \text {, devido a } \\
\text { apresentar efeito analgésico similar } \\
\text { à dipirona; } \\
\text { - Contraindicado: história de } \\
\text { gastrite, hipertensão arterial, úlcera } \\
\text { péptica e doença renal; } \\
\text { - Inibidor não seletivo para COX-2; } \\
\text { - Contraindicado para pacientes } \\
\text { asmáticos; } \\
\text { - Evitar: história de } \\
\text { hipersensibilidade ao AAS (riso de } \\
\text { alergia cruzada). }\end{array}$ \\
\hline
\end{tabular}




\begin{tabular}{|c|c|c|c|}
\hline $\begin{array}{l}\text { Cetorolaco } \\
\left(\text { Deocil }{ }^{\circledR}\right) \\
\text { (Comprimido) }\end{array}$ & $\begin{array}{l}\text { Terapêutico: } 10 \mathrm{mg} \text { de } 06 \text { em } 06 \text { horas } \\
\text { ou } 08 \text { em } 08 \text { horas }\end{array}$ & $\begin{array}{l}\text { Uso interno/Via } \\
\text { Sublingual }\end{array}$ & $\begin{array}{l}\text { - Pacientes com distúrbios da } \\
\text { coagulação sanguínea não devem } \\
\text { receber Deocil }{ }^{\circledR} \text {; } \\
\text { - Inibidor não seletivo para COX-2; } \\
\text { - Máximo de dias para a duração do } \\
\text { tratamento: } 2 \text { à 3; } \\
\text { - Indicado para dor aguda; } \\
\text { - Início de ação 30-60 minutos; } \\
\text { - Contraindicado para paciente } \\
\text { portador de insuficiência cardíaca } \\
\text { grave; } \\
\text { - Contraindicado para pacientes } \\
\text { asmáticos; } \\
\text { - Não associar a qualquer outro } \\
\text { AINES! }\end{array}$ \\
\hline $\begin{array}{l}\text { Diclofenaco de Sódio } \\
\text { (Voltaren }{ }^{\circledR} ; \text { Fisioren }{ }^{\circledR} \\
\text { (Comprimido revestido) }\end{array}$ & Terapêutico: 50 mg de 08 em 08 horas & Uso interno/Via Oral & $\begin{array}{l}\text { - Contraindicação: úlcera de } \\
\text { estômago e intestino, alergia ao } \\
\text { diclofenaco ou a outro componente } \\
\text { da fórmula como o aspartame, crise } \\
\text { de asma, urticária e rinite aguda; } \\
\text { - Máximo de dias para a duração do } \\
\text { tratamento: } 2 \text { à 3; } \\
\text { - Inibidor não seletivo para COX-2; } \\
\text { - Contraindicado para pacientes } \\
\text { asmáticos; } \\
\text { - Não tomar com aspirina ou outros } \\
\text { medicamentos com atividade } \\
\text { inibidora da prostaglandina. }\end{array}$ \\
\hline $\begin{array}{c}\text { Diclofenaco de Potássio } \\
\text { (Cataflam }{ }^{\circledR} ; \text { Zorvolex }{ }^{\circledR} \text { ) } \\
\text { (Comprimido revestido) }\end{array}$ & Terapêutico: 50 mg de 08 em 08 horas & Uso interno/Via Oral & $\begin{array}{l}\text { - Contraindicação: úlcera de } \\
\text { estômago e intestino, alergia ao } \\
\text { diclofenaco, crise de asma, urticária } \\
\text { e rinite aguda; } \\
\text { - Máximo de dias para a duração do } \\
\text { tratamento: } 2 \text { à 3; } \\
\text { - Inibidor não seletivo para COX-2; } \\
\text { - Contraindicado para pacientes } \\
\text { asmáticos; } \\
\text { - Não tomar com aspirina ou outros } \\
\text { medicamentos com atividade } \\
\text { inibidora da prostaglandina. }\end{array}$ \\
\hline $\begin{array}{c}\text { Etoricoxibe } \\
\left(\text { Arcoxia }{ }^{\circledR}\right) \\
\text { (Comprimido revestido) }\end{array}$ & $\begin{array}{l}\text { Terapêutico: } 60 \text { - } 90 \text { mg de } 12 \text { em } 12 \text { ou } \\
24 \text { em } 24 \text { horas }\end{array}$ & $\begin{array}{l}\text { Uso interno/Via } \\
\text { Oral }\end{array}$ & $\begin{array}{l}\text { - Máximo de dias para a duração do } \\
\text { tratamento: } 2 \text { à 3; } \\
\text { - Contraindicado para pacientes } \\
\text { asmáticos; } \\
\text { - Inibidor específico para COX-2; } \\
\text { - Necessidade de prescrição em } \\
\text { receituário de controle especial. }\end{array}$ \\
\hline $\begin{array}{c}\text { Celecoxibe } \\
\left(\text { Celebra }{ }^{\circledR}\right) \\
\text { (Comprimido revestido) }\end{array}$ & Terapêutico: 200 mg de 24 em 24 horas & Uso interno/Via Oral & $\begin{array}{l}\text { - Máximo de dias para a duração do } \\
\text { tratamento: } 2 \text { à 3; } \\
\text { - Contraindicado para pacientes } \\
\text { asmáticos; } \\
\text { - Inibidor específico para COX-2; } \\
\text { - Necessidade de prescrição em } \\
\text { receituário de controle especial. }\end{array}$ \\
\hline
\end{tabular}




\begin{tabular}{|c|c|c|c|}
\hline $\begin{array}{c}\text { Dipirona } \\
\left(\text { Novalgina }{ }^{\circledR}\right) \\
\text { (Comprimido ou gotas) }^{\text {(Comprido }}\end{array}$ & $\begin{array}{l}\text { Terapêutico: } 1 \mathrm{~g} \text { de } 04 \text { em } 04 \text { ou de } 06 \\
\text { em } 06 \text { horas } \\
\text { Terapêutico: (Gotas) } 40 \text { gotas de } 04 \text { em } \\
04 \text { ou de } 06 \text { em } 06 \text { horas. } \\
\text { Em pacientes pediátricos: } 500 \mathrm{mg} / \mathrm{ml}- \\
0,5 \text { a } 1 \text { gota por kg, } 04 \text { em } 04 \text { ou de } 06 \\
\text { em } 06 \text { horas. }\end{array}$ & Uso interno/ViaOral & $\begin{array}{l}\text { - Contraindicação: pacientes com } \\
\text { alergia a pirazolona, doenças } \\
\text { metabólicas hepática, crianças < } \\
\text { que } 3 \text { meses e < que } 5 \mathrm{~kg} \text {; } \\
\text { - Evitar: gravidez ( } 3 \text { primeiros } \\
\text { meses e últimas } 6 \text { semanas), } \\
\text { lactantes (amamentação após } 48 \mathrm{hs)} \\
\text { e pacientes com história de anemia } \\
\text { ou leucopenia; } \\
\text { - Analgésico eficaz e seguro em } \\
\text { odontologia (droga padrão ouro do } \\
\text { grupo: deprime os nociceptores já } \\
\text { sensibilizados); com cautela em } \\
\text {-Administrar com } \\
\text { pacientes com condições } \\
\text { circulatórias instáveis } \\
\text { sistólica<100mmHg) } \\
\text { endovenosa. VAia }\end{array}$ \\
\hline $\begin{array}{l}\text { Paracetamol } \\
\left.\text { (Tylenol }^{\circledR}\right) \\
\text { (Comprimido) }\end{array}$ & $\begin{array}{l}\text { Terapêutico: } 500 \text { mg de } 04 \text { em } 04 \text { horas } \\
\text { Terapêutico: } 750 \mathrm{mg} \text { de } 06 \text { em } 06 \text { ou de } \\
08 \text { em } 08 \text { horas } \\
\text { Terapêutico: dose pediátrica: } 1 \\
\text { gota/kg de } 04 \text { em } 04 \text { ou } 06 \text { em } 06 \text { horas }\end{array}$ & Uso interno/Via Oral & $\begin{array}{l}\text { - Não ultrapassar a dose máxima } \\
\text { diária de } 3,25 \mathrm{~g} / \text { dia; } \\
\text { - Evitar seu uso em pacientes } \\
\text { elitistas (alcoolismo crônico), } \\
\text { sedativos e anticonvulsivantes; } \\
\text { - Evitar prescrição em conjunto } \\
\text { com nimesulida e amoxicilina com } \\
\text { Clavulanato de potássio; } \\
\text { - Evitar a utilização de grandes } \\
\text { doses de prilocaína } 3 \% \text {. }\end{array}$ \\
\hline $\begin{array}{c}\text { Cloridrato de tramadol } \\
\left.\text { (Anangor }^{\circledR} ; \text { Sylador }^{\circledR} ; \text { Tramal }^{\circledR}\right) \\
(\text { Comprimido })\end{array}$ & Terapêutico: 50 mg de 08 em 08 horas & Uso interno/Via Oral & $\begin{array}{l}\text { - Indicado para pacientes alérgicos } \\
\text { à analgésicos não opióides; } \\
\text { - Não ultrapassar a dose diária de } \\
400 \text { mg/dia; } \\
\text { - Contraindicado para pacientes em } \\
\text { tratamento com inibidores da MAO, } \\
\text { ou pacientes que foram tratados } \\
\text { com esse fármaco nos últimos } 14 \\
\text { dias; } \\
\text { - Contraindicado para menores de } \\
16 \text { anos (sem estudos clínicos } \\
\text { controlados); } \\
\text { - Uso com cautela em pacientes } \\
\text { idosos, com insuficiência hepática } \\
\text { ou renal, hipertrofia prostática e } \\
\text { portadores de depressão } \\
\text { respiratória; } \\
\text { - Efeito adverso: náuseas, } \\
\text { constipação intestinal, vômito, } \\
\text { alteração de humor, sonolência e } \\
\text { depressão respiratória. }\end{array}$ \\
\hline $\begin{array}{c}\text { Codeína } \\
\left(\text { Tylex }^{\circledR} ; \text { Codex }^{\circledR} ; \text { Vicodi }^{\circledR}\right) \\
(\text { Comprimido })\end{array}$ & $\begin{array}{l}\text { Terapêutico: Dor leve: } 500 \mathrm{mg} \text { de } \\
\text { paracetamol }+7,5 \mathrm{mg} \text { de codeína de } 06 \\
\text { em } 06 \text { horas } \\
\text { Terapêutico: Dor moderada a intensa: } \\
500 \mathrm{mg} \text { de paracetamol }+30 \mathrm{mg} \text { de } \\
\text { codeína de } 06 \text { em } 06 \text { horas }\end{array}$ & Uso interno /Via Oral & $\begin{array}{l}\text { - Indicado para pacientes alérgicos } \\
\text { à analgésicos não opióides; } \\
\text { - Contraindicação: Em casos de } \\
\text { diarreia associada à colite } \\
\text { pseudomembranosa causada por } \\
\text { cefalosporina, lincomicina ou } \\
\text { penicilina, paciente menores de } 2 \\
\text { anos, gravidez, amamentação, } \\
\text { depressão respiratória aguda e em } \\
\text { casos de dependência de droga, } \\
\text { inclusive alcoolismo; } \\
\text { - Pode estar associado ao } \\
\text { Paracetamol ou Diclofenaco de } \\
\text { sódio; } \\
\text { - Reações adversas: constipação e } \\
\text { sonolência; } \\
\text { - Inibe o centro da tosse. Não reagir } \\
\text { frente a estímulos. }\end{array}$ \\
\hline
\end{tabular}




\begin{tabular}{|c|c|c|c|}
\hline $\begin{array}{c}\text { Nistatina } \\
\left(\text { Nidazolin }^{\circledR} ; \text { Nistrazin }{ }^{\circledR} ; \text { Micostatin }{ }^{\circledR}\right) \\
(\text { Suspensão oral e elixir })\end{array}$ & $\begin{array}{l}\text { Suspensão oral: } 100.000 \mathrm{UI} / \mathrm{mL} \\
\text { Elixir: Espalhar pela boca a medida de } \\
01 \text { colher de sopa ( } 10 \mathrm{~mL}) \text {, por } 01 \text { a } 03 \\
\text { minutos. } 04 \text { vezes ao dia. Durante } 14 \text { - } \\
21 \text { dias. } \\
\text { Usuário de prótese: Colocar } 5 \text { gotas na } \\
\text { prótese antes de utilizar. }\end{array}$ & $\begin{array}{c}\text { Uso interno/Via } \\
\text { Bucal }\end{array}$ & $\begin{array}{l}\text { - Se houver comprometimento de } \\
\text { orofaringe, o mesmo deverá engolir. } \\
\text { Caso contrário, desprezar. }\end{array}$ \\
\hline $\begin{array}{c}\text { Miconazol } \\
\left(\text { Daktarin }{ }^{\circledR}-\text { gel oral }\right) \\
(\text { gel })\end{array}$ & $\begin{array}{l}20 \mathrm{mg} / \mathrm{g} \text { (Gel Oral): Aplicar na região da } \\
\text { lesão } 04 \text { vezes ao dia durante } 21 \text { dias. } \\
\text { Usuário de prótese: Aplicar uma fina } \\
\text { camada na prótese antes de utilizar. }\end{array}$ & $\begin{array}{c}\text { Via enteral/Uso } \\
\text { Bucal }\end{array}$ & $\begin{array}{l}\text { - Durante o seu uso, deve-se evitar } \\
\text { a prescrição de outro medicamento } \\
\text { na área infectada, principalmente } \\
\text { produtos de caráter ácido, devido à } \\
\text { inativação do miconazol em faixas } \\
\text { baixas de pH. }\end{array}$ \\
\hline $\begin{array}{c}\text { Fluconazol } \\
\left.\text { (Flucocin }^{\circledR} ; \text { Zoltec }^{\circledR}\right) \\
\text { (Cápsula) }\end{array}$ & $\begin{array}{l}\text { Cápsula } 150 \mathrm{mg} \text { : Tomar } 01 \text { comprimido } \\
\text { via oral } 01 \text { vez por semana durante } 3-4 \\
\text { semanas. }\end{array}$ & Uso interno/Via Oral & $\begin{array}{l}\text { - Indicação: Candidíase das } \\
\text { mucosas, incluindo as candidoses } \\
\text { orofaríngeas, esofágicas, } \\
\text { mucocutâneas e broncopulmonares } \\
\text { não invasivas. } \\
\text { - Contraindicação: não usar } \\
\text { concomitante com a eritromicina. }\end{array}$ \\
\hline $\begin{array}{l}\text { Diazepam } \\
\left.\text { (Valium }^{\circledR}\right)\end{array}$ & $\begin{array}{l}\text { Pré-operatório: Adultos: } 5 \mathrm{mg} \text { a } 10 \mathrm{mg} \text { - } \\
1 \text { hora antes do procedimento. } \\
\text { Pré-operatório: Crianças: } 0,2-0,5 \mathrm{mg} / \mathrm{kg} \\
\text { - } 1 \text { hora antes do procedimento. }\end{array}$ & Uso interno/Via Oral & $\begin{array}{l}\text { - Efeito sobre a capacidade de } \\
\text { dirigir veículo e operar máquinas } \\
\text { (aguardar } 24 \text { horas); } \\
\text { - Não indicado para idosos; } \\
\text { - Início de ação: } 60 \text { minutos; } \\
\text { - Duração: } 12 \text { à } 24 \text { horas. } \\
\text { - Contraindicações: Portadores de } \\
\text { insuficiência respiratória grave; } \\
\text { Portadores de glaucoma de ângulo } \\
\text { estreito; Portadores de miastenia } \\
\text { grave; Gestantes(10 trimestre ao } \\
\text { final da gestação); Crianças com } \\
\text { comprometimento físico ou mental } \\
\text { severo; História } \\
\text { hipersensibilidade } \\
\text { benzodiazepínicos; Apneia do sono; } \\
\text { Etilistas. }\end{array}$ \\
\hline $\begin{array}{c}\text { Midazolam } \\
\text { (Midazolam }^{\circledR} ; \text { Sonolam }^{\circledR} ; \\
\left.\text { Hipnazolam }^{\circledR}\right)\end{array}$ & $\begin{array}{l}\text { Pré-operatório: Adultos: } 7,5-15 \mathrm{mg}-30 \\
\text { a } 45 \text { minutos antes do procedimento. } \\
\text { Pré-operatório: Crianças: } 0,25-0,5 \\
\mathrm{mg} / \mathrm{kg}-30 \text { a } 45 \text { minutos antes do } \\
\text { procedimento. }\end{array}$ & Uso interno/Via Oral & $\begin{array}{l}\text { - Causa amnésia anterógrada; } \\
\text { - Sonolência; } \\
\text { - Mais indicado em pacientes } \\
\text { pediátricos; } \\
\text { - Efeito sobre a capacidade de } \\
\text { dirigir veículo e operar máquinas } \\
\text { (aguardar } 24 \text { horas); } \\
\text { - Hipnótico; } \\
\text { - Início de ação: } 30 \text { minutos; } \\
\text { - Duração: } 1 \text { à } 2 \text { horas; } \\
\text { - Contraindicações: Portadores de } \\
\text { insuficiência respiratória grave; } \\
\text { Portadores de glaucoma de ângulo } \\
\text { estreito; Portadores de miastenia } \\
\text { grave; Gestantes(10 trimestre ao } \\
\text { final da gestação); Crianças com } \\
\text { comprometimento físico ou mental } \\
\text { severo; História a de } \\
\text { hipersensibilidade } \\
\text { benzodiazepínicos; Apneia do sono; } \\
\text { Etilistas. }\end{array}$ \\
\hline
\end{tabular}




\begin{tabular}{|c|c|c|c|}
\hline $\begin{array}{c}\text { Clonazepam } \\
{\left(\text { Clopam }^{\circledR} ; \text { Zilepam }^{\circledR} ; \text { Rivotril }^{\circledR}\right)}^{(\text {Solução) }}\end{array}$ & $\begin{array}{l}\text { Solução oral } 2,5 \mathrm{mg} / \mathrm{ml} \text { : Aplicar } 2-5 \\
\text { gotas sobre a língua } 01 \text { vez ao dia } \\
\text { (noite). Durante } 1-3 \text { meses. }\end{array}$ & Uso interno/Via Bucal & $\begin{array}{l}\text { • Indicação: Síndrome da ardência } \\
\text { bucal }\end{array}$ \\
\hline $\begin{array}{l}\text { Naproxeno sódico } \\
\left.\text { (Flanax }{ }^{\circledR}\right) \\
\text { (comprimido) }\end{array}$ & $\begin{array}{l}\text { Terapêutico: } 550 \mathrm{mg} \text { de } 24 \text { em } 24 \\
\text { horas }\end{array}$ & Uso interno/Via Oral & $\begin{array}{l}\text { - Contraindicação: Evitar utilizar } \\
\text { naproxeno sódico com AINES }\end{array}$ \\
\hline $\begin{array}{c}\text { Ciclobenzaprina } \\
\left(\text { Miosan }{ }^{\circledR}\right) \\
\text { (comprimido revestido) }\end{array}$ & $\begin{array}{l}\text { Terapêutico: } 5 \mathrm{mg} \text { de } 06 \mathrm{em} 06 \text { horas } \\
\text { ou } 10 \mathrm{mg} \text { da } 12 \mathrm{em} 12 \text { horas }\end{array}$ & Uso interno/Via Oral & $\begin{array}{l}\text { - Ciclobenzaprina diminui o fluxo } \\
\text { salivar }\end{array}$ \\
\hline $\begin{array}{c}\text { Dipirona monoidratada, citrato de } \\
\text { orfenadrina e cafeína anidra } \\
\left.\text { (Dorflex }{ }^{\circledR}\right) \\
\text { (Comprimido) }\end{array}$ & $\begin{array}{l}\text { Terapêutico: } 1 \text { a } 2 \text { comprimidos, de } 3 \text { a } \\
4 \text { vezes por dia }\end{array}$ & Uso interno/Via Oral & $\begin{array}{l}\text { - Dorflex é contraindicado para } \\
\text { pacientes alérgicos a dipirona. }\end{array}$ \\
\hline $\begin{array}{c}\text { Carisoprodol } \\
\left(\text { Mioflex }{ }^{\circledR}\right) \\
(\text { Comprimido })\end{array}$ & $\begin{array}{l}\text { Terapêutico: Dose mínima: um } \\
\text { comprimido de } 12 \text { em } 12 \text { horas. Dose } \\
\text { máxima: um comprimido de } 08 \text { em } 08 \\
\text { horas. }\end{array}$ & Uso interno/Via Oral & $\begin{array}{l}\text { - Carisoprodol é recomendado para } \\
\text { pacientes que são sensíveis à } \\
\text { ciclobenzaprina. }\end{array}$ \\
\hline $\begin{array}{c}\text { Ciclobenzaprina + cafeína } \\
\left(\text { Miosan } \operatorname{Caf}^{\circledR}\right) \\
\text { (Comprimido revestido) }\end{array}$ & $\begin{array}{l}\text { Terapêutico: } 1 \text { comprimido a cada } 12 \\
\text { horas ou a cada } 06 \text { horas. Dose máxima } \\
60 \mathrm{mg}\end{array}$ & Uso interno/Via Oral & $\begin{array}{l}\text { - Ciclobenzaprina + cafeína diminui } \\
\text { o fluxo salivar. }\end{array}$ \\
\hline $\begin{array}{c}\text { Capsaicina } \\
\left(\text { Moment }^{\circledR}\right) \\
(\text { Creme }) \\
\end{array}$ & $\begin{array}{l}\text { Creme } \mathbf{0 , 0 2 5} \% \text { e } \mathbf{0 , 0 7 5} \% \text { : Aplicar uma } \\
\text { fina camada na área afetada de } 3-4 \\
\text { vezes ao dia. Durante } 1-3 \text { meses. }\end{array}$ & Uso interno/Via Bucal & $\begin{array}{l}\text { - Indicação: Síndrome da ardência } \\
\text { bucal. }\end{array}$ \\
\hline $\begin{array}{l}\text { Pentoxifilina } \\
\left(\text { Trental }{ }^{\circledR}\right) \\
\text { (Comprimido) } \\
\end{array}$ & $\begin{array}{l}400 \mathrm{mg} \text { : Tomar } 01 \text { comprimido de } 12 \\
\text { em } 12 \text { horas. Durante } 1-3 \text { meses. }\end{array}$ & Uso interno/Via Oral & - Indicação: Necroses ósseas. \\
\hline $\begin{array}{c}\text { Tocoferol } \\
\text { (Vitamina E) } \\
\text { (Comprimido) } \\
\end{array}$ & $\begin{array}{l}5.000 \text { UI: Tomar } 01 \text { comprimido de } 12 \\
\text { em } 12 \text { horas. Durante } 1-3 \text { meses. }\end{array}$ & Uso interno/Via Oral & - Indicação: Necroses ósseas. \\
\hline $\begin{array}{l}\text { Bicarbonato de sódio } \\
\text { (Pó) }\end{array}$ & $\begin{array}{l}\text { Dissolver } 01 \text { colher de chá rasa em } 01 \\
\text { copo de água em } 200 \mathrm{~mL} \text {. Bochechar } 03 \\
\text { vezes ao dia como parte da higiene oral. } \\
\text { Para usuário de prótese: Colocar as } \\
\text { próteses nesta solução no período } \\
\text { noturno. }\end{array}$ & Uso interno/Via Bucal & $\begin{array}{l}\text { - Indicação: Candidíase. } \\
\text { • Indicação: Para neutralizar o meio } \\
\text { bucal. }\end{array}$ \\
\hline $\begin{array}{l}\text { Pilocarpina } \\
\text { (colírio) }\end{array}$ & $\begin{array}{l}\text { 1\%: } 1 \text { gota/cada } 7,5 \mathrm{~kg} \text { de peso; } 3 \text { vezes } \\
\text { por dia sublingual. Começar com } 1 \text { gota, } \\
\text { aumentar } 1 \text { gota/dia, até no máximo } 8 \\
\text { gotas. }\end{array}$ & $\begin{array}{l}\text { Uso externo/Via } \\
\text { ocular }\end{array}$ & $\begin{array}{l}\text { - Contraindicação: asma, glaucoma } \\
\text { e alterações cardíacas. Em caso de } \\
\text { efeito colateral, voltar ao esquema } \\
\text { do dia anterior e manter durante } 30 \\
\text { dias. Fazer desmame (gota-a-gota). }\end{array}$ \\
\hline $\begin{array}{c}\text { Saliva artificial } \\
\text { (bioXtra, Kin Hidrat, Saliform, } \\
\text { Maninpulaçâo) } \\
\end{array}$ & Aplicar sempre que sentir a boca seca. & Uso interno/Via Bucal & $\begin{array}{l}\text { - Indicação: Xerostomia. } \\
\text { - Indicação: Hipossalivação. }\end{array}$ \\
\hline $\begin{array}{c}\text { Dióxido de cloro estabilizado } \\
\left.\text { (Halicare }{ }^{\circledR}\right)\end{array}$ & $\begin{array}{l}\text { Fazer bochecho } 3 \text { veze ao dia após } \\
\text { higiene oral. }\end{array}$ & Uso interno/Via Bucal & $\begin{array}{l}\text { - Dióxido de cloro estabilizado é } \\
\text { indicado para hipossalivação e } \\
\text { halitose. }\end{array}$ \\
\hline Bepantol $^{\circledR}$ Baby & Aplicar nos lábios para hidratação. & Uso interno/Via Bucal & • Indicação: Lábios ressecados. \\
\hline $\begin{array}{l}\text { Solução enzimática } \\
\left.\text { (bioXtra }{ }^{\circledR}\right)\end{array}$ & $\begin{array}{l}\text { Fazer bochecho } 3 \text { vezes ao dia após } \\
\text { higiene oral. }\end{array}$ & Uso interno/Via Bucal & $\begin{array}{l}\text { - Indicação: Xerostomia. } \\
\text { - Indicação: Hipossalivação. }\end{array}$ \\
\hline
\end{tabular}




\section{II.2 Como redigir uma correta prescrição medicamentosa?}

1. Identificação da Instituição ou do profissional

2. Cabeçalho

- Nome do paciente; Endereço; Vias de administração do medicamento

\begin{tabular}{|c|l|}
\hline USO INTERNO & \multicolumn{1}{|c|}{ USO EXTERNO } \\
\hline Oral, Sublingual, Bucal, Retal & $\begin{array}{l}\text { Percutânea, Intramuscular, } \\
\text { Intravenosa, subcutânea, Intra- } \\
\text { articular, Inalatória, Submucosa e } \\
\text { subperióstea. }\end{array}$ \\
\hline
\end{tabular}

3. Inscrição

- Nome do medicamento; Concentração do medicamento;

Quantidade total do medicamento prescrito pelo profissional.

4. Orientação

(Explicação ao paciente sobre como fazer o uso do medicamento)

- Dose; Horários; Duração.

OBSERVACÃO 1: Informações relativas aos cuidados pós-operatórios deverão estar contidas fora do corpo da prescrição de medicamentos, em uma folha de receituário anexa ou por meio de impressos explicativos.

OBSERVACÃO 2: Evitar deixar espaços em branco na prescrição.

OBSERVACÃO 3: A prescrição medicamentosa deve ser realizada em letra legível (de preferencia em letra de forma) quando escrita a mão. Porém, o profissional pode optar em realiza-la pelo computador tendo apenas a obrigatoriedade de sua assinatura e data escritas à caneta.

OBSERVACÃO 4: Antibióticos, analgésicos opioides e antiinflamatórios específicos de COX-2 devem ser prescritos em receituário de controle especial receituário tipo $\mathrm{C}$ (cor branca).

OBSERVACÃO 5: Ansiolíticos e benzodiazepínicos devem ser prescritos em receituário tipo $B$ (cor azul).

5. Nome, $\mathrm{n}^{\circ}$ do CRORJ, Data e assinatura do profissional

6. Endereço da instituição ou consultório do profissional 


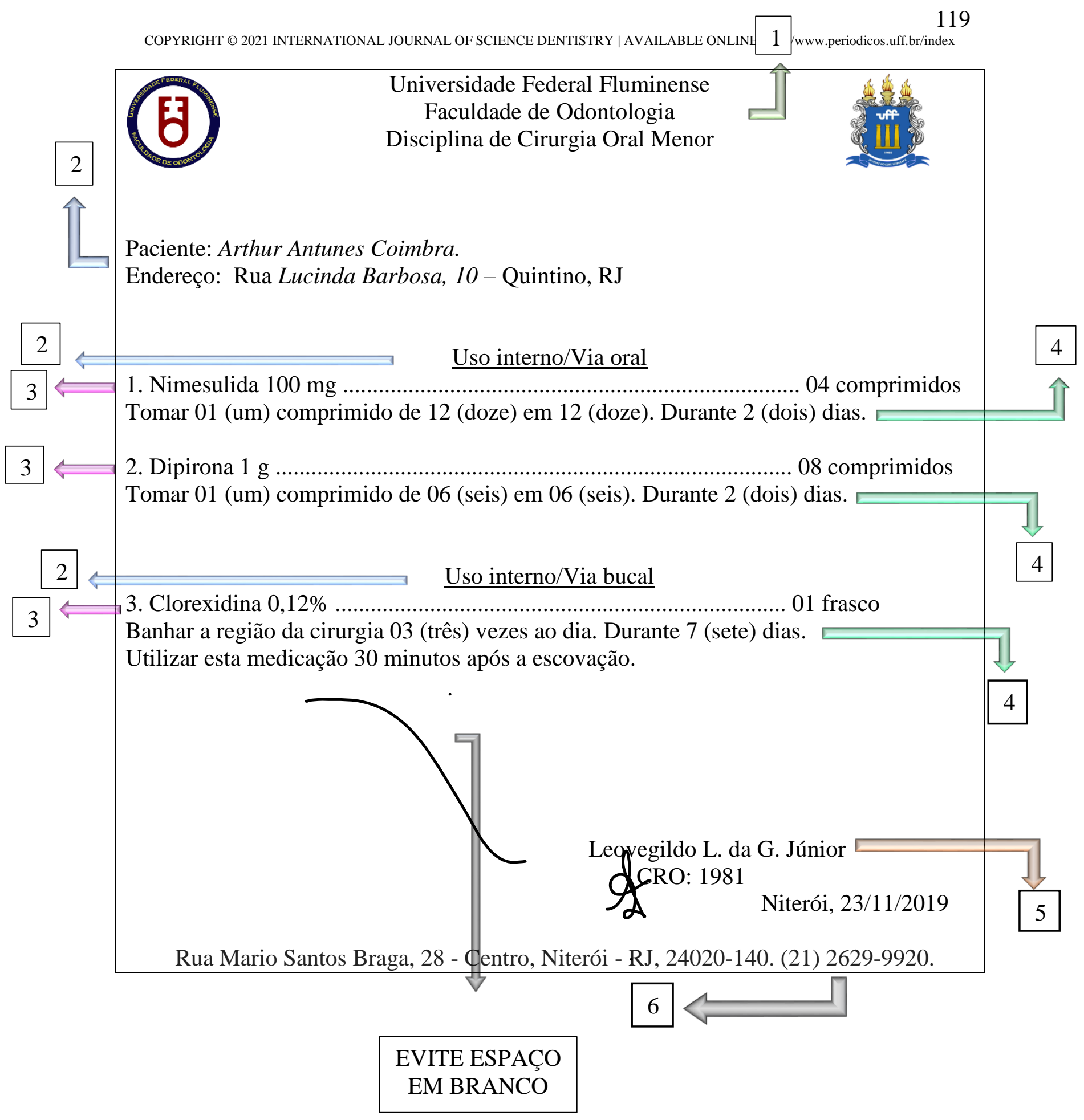




\section{CONCLUSÃO}

O uso da tabela nas clínicas odontológicas visa ofertar ao aluno acesso aos principais medicamentos juntamente com os aspectos conceituais e fundamentais para confecção de uma receita clara e objetiva. Essa medida educativa, portanto, minimiza os problemas acerca da terapêutica e da farmacologia e colabora com a segurança do futuro profissional na tomada de decisões para o melhor tratamento medicamentoso.

\section{REFERÊNCIAS}

1. Pepe, V. L. E., Castro, C. G. S. O. A interação entre prescritores, dispensadores e pacientes: informação compartilhada como possível benefício terapêutico. Cad. Saúde Pública. 2000; 16 (3): 815-22.

2. Gleicy Fátima Medeiros de Souza, Kelly Fabíola Freitas Borges da Silva, André Ricardo Moreira de Brito. Prescrição medicamentosa em Odontologia: normas e condutas. 8 Cad. Saúde Colet., 2011, Rio de Janeiro, 19 (2): 208-214.

3. Brito, T. A., Castilho, L. S., Paixão, H. H. Os estudantes de odontologia e a (in) segurança para prescrever medicamentos. Arq. Centro Estud. Curso de Odontol. 1996; 32 (1): 51-64.

4. Andrade, E. D. Terapêutica Medicamentosa em Odontologia - Artes Médicas, $3^{\text {a }}$ E 6 2014.

5. Yagiela, J.A. Farmacologia e terapêutica para dentistas - Elsevier Editora, $6^{\circ}$ ED., 2011

6. www.anvisa.gov.br. Visto em 28 de fevereiro de 2020 às 17:52h.

7. A guideline from the American Heart Association - Rheumatic Fever, Endocarditis, and Kawasaki Disease Committee, Council on Cardiovascular Disease in the Young, and the Council on Clinical Cardiology, Council on Cardiovascular Surgery and Anesthesia, and the Quality of Care and Outcomes Research Interdisciplinary Working Group. Circulation. 2007;116:1736-1754.

8. ADA. Antibiotic prophylaxis prior to dental procedures. Oral Health Topics 2017 [cited 31st March 2017]; Available from: http://www.ada.org/en/member-center/ oralhealth-topics/antibiotic-prophylaxis. 